\title{
Aplikasi Transformasi Laplace pada Sistem Dinamik Pendulum Terbalik dengan Redaman dan Gaya Penggerak
}

\author{
Dewi Fairuz Zulaikha, Warsono
}

Program Studi Magister Pendidikan Fisika, Universitas Negeri Yogyakarta, Indonesia. E-mail: dewifairuz.2020@student.uny.ac.id

\begin{abstract}
Abstrak
Pendulum terbalik merupakan suatu sistem non-linear, multivariabel, tidak stabil dan merupakan tolak ukur yang sangat baik untuk menguji algoritma kontrol yang berbeda. Dalam beberapa tahun terakhir, minat para peneliti di bidang sistem kontrol pada pendulum terbalik meningkat. Persamaan gerak pada sistem pendulum merupakan persamaan diferensial yang dapat dianalisis menggunakan Transformasi Laplace. Aljabar tersebut menjadi rumit pada suatu kejadian dan dapat lebih mudah jika diselesaikan menggunakan transformasi Laplace daripada jika diselesaikan dengan analisis persamaan diferensial secara langsung. Tujuan dari penelitian ini adalah untuk menyelesaikan persamaan diferensial dari hasil Lagrangian pada sistem dinamik pendulum terbalik menggunakan transformasi Laplace. Metode yang digunakan untuk menyelesaikan persamaan diferensial adalah menggunakan Mekanika Lagrange dan Tranformasi Laplace. Analisis dengan Lagrangian digunakan untuk menentukan persamaan diferensial orde 2 pada sistem. Kemudian persamaan diferensial tersebut diselesaikan dengan menggunakan transformasi Laplace dan invers transformasi Laplace sehingga diperoleh persamaan akhir dalam domain waktu (t).
\end{abstract}

Kata kunci: Transformasi Laplace; Sistem Dinamik; Pendulum Terbalik; Gaya Penggerak Pendulum

\section{Pendahuluan}

Pendulum adalah sistem yang dinamis (Agarana, M C \& Agboola, 2015). Pendulum biasanya memiliki poros di bagian atas dan massa di bagian bawah (Agarana, Michael C. \& Ajayi, 2017). Pendulum yang memiliki titik pusat massa di atas titik baliknya dinamakan pendulum terbalik/ inverted pendulum (Michael et al., 2019). Tidak seperti pendulum biasa yang selalu stabil ketika digantungkan ke bawah, pendulum terbalik adalah suatu sistem yang tidak stabil dan harus diseimbangkan agar tetap tegak (Agarana, Michael C. \& Ajayi, 2017). Pendulum terbalik merupakan suatu sistem yang non-linear, multivariabel, tidak stabil dan merupakan tolak ukur yang sangat baik untuk menguji algoritma kontrol yang berbeda (Mandic et al., 2017). Sistem pendulum terbalik adalah persoalan umum yang sering digunakan untuk mendemonstrasikan aplikasi dari sistem kendali untuk menstabilkan suatu sistem plant (Sablina et al., 2015), (Rizal \& Mantala, 2016).

Dalam beberapa tahun terakhir, minat para peneliti di bidang sistem kontrol pada pendulum terbalik meningkat (Mandic et al., 2017), (Tin et al., 2019) karena kesamaan mendasar dari sistem pendulum terbalik dengan berbagai sistem praktik, seperti keseimbangan tongkat, gaya berjalan manusia, keseimbangan peluncur roket dan gerakan vertikal lengan manusia (Bandari et al., 2017). Pendulum terbalik adalah suatu mekanisme untuk membawa objek dari satu tempat ke tempat yang lain dan terlihat fungsinya saat berjalan (Agarana, Michael C. \& Ajayi, 2017). Sistem pendulum terbalik juga banyak diaplikasikan dalam berbagai bidang seperti di dunia robotik, proses industri, dan multi-teknologi atau kombinasi organik ( $\mathrm{Su}$ et al., 2018) serta menjadi persoalan yang sangat penting baik di dunia teori maupun praktik (Tin et al., 2019).

Persamaan gerak pada sistem pendulum merupakan persamaan diferensial yang dapat dianalisis menggunakan Transformasi Laplace. Metode Transformasi Laplace (Laplace transform) menganalisis suatu persamaan diferensial dengan memetakan masalah nilai awal ke dalam suatu persamaan aljabar atau suatu sistem persamaan yang dapat diselesaikan dengan metode aljabar dan tabel pada transformasi Laplace (Arifin et al., 2013). Aljabar tersebut menjadi rumit pada suatu kejadian dan dapat lebih mudah jika diselesaikan menggunakan transformasi Laplace daripada jika 
diselesaikan dengan analisis persamaan diferensial secara langsung (Minggani, 2019).

Tujuan dari penelitian ini adalah untuk menyelesaikan persamaan diferensial dari hasil Lagrangian pada sistem dinamik pendulum terbalik menggunakan transformasi Laplace. Pengaruh dari dinamika pendulum terbalik pada penelitian ini ditunjukkan dengan persamaan kecepatan sudut sebagai fungsi waktu.

\section{Pembahasan}

\subsection{Penyelesaian Persamaan Diferensial dengan Transformasi Laplace}

Secara umum, transformasi Laplace didefinisikan dengan:

$$
\mathcal{L}\{f(t)\}=F(s)=\int_{0}^{\infty} e^{-s t} f(t) d t
$$

dengan $\quad t>0, \quad \mathcal{L}$ merupakan operator transformasi Laplace, $e^{-s t}$ merupakan fungsi kernel transformasi dan $s$ merupakan variabel transformasi (Appel, 2007), (Arfken \& Weber, 2016), (Boas, 2006), (Kusse \& Westwig, 2006), (Riley et al., 2006).

Langkah-langkah dalam mencari penyelesaian dari suatu persamaan diferensial dengan menggunakan transformasi Laplace adalah (Agarana, M C \& Agboola, 2015), (Arifin et al., 2013):

a. Melakukan transformasi Laplace pada kedua ruas persamaan

b. Menyederhanakan hasil yang diperoleh secara aljabar. Jika mengandung pecahan parsial, maka analisis dengan menggunakan metode penjumlahan pecahan parsial.

c. Mencari invers transformasi Laplace untuk menentukan fungsi dalam domain $t$. Hasil dari transformasi Laplace invers adalah solusi dari persamaan diferensial yang diberikan.

\subsection{Pemodelan dari Sistem Pendulum Terbalik dengan Redaman dan Gaya Penggerak}

Ilustrasi dari sistem pendulum terbalik dapat dilihat pada Gambar 1

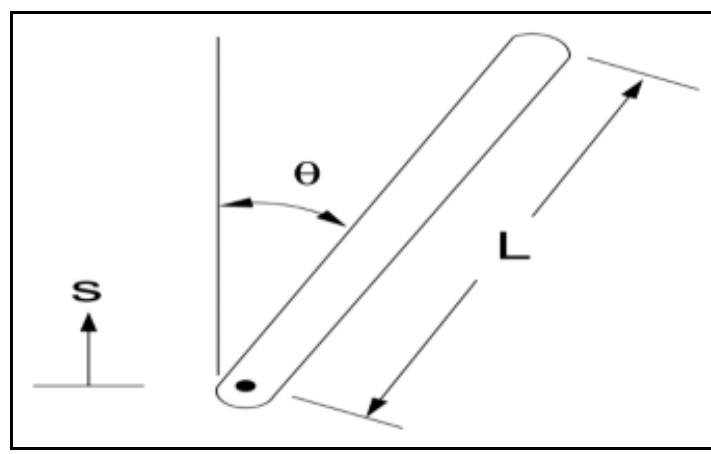

Gambar 1. Sistem Pendulum Terbalik

Komponen vertikal dan horizontal dari panjang tali pada pendulum terbalik dapat dilihat pada Gambar 2.

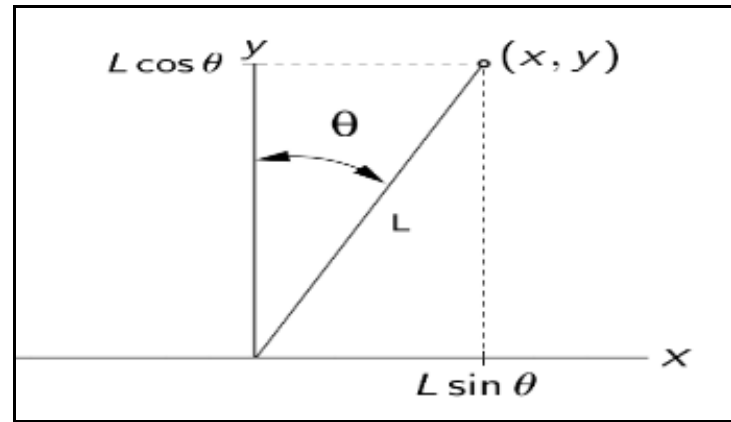

Gambar 2. Komponen vertikal dan horizontal dari panjang tali pada pendulum terbalik

Mekanika Langrange cocok untuk sistem dengan gaya konservatif dan untuk mengatasi gaya yang berlaku pada sistem koordinat apa saja dengan menganalisisnya menggunakan energi (baik energi kinetik maupun energi potensial) (Agarana, Michael C. \& Ajayi, 2017). Lagrangian didefinisikan dengan:

$$
L=T-V
$$

dimana $T$ dan $V$ berturut-turut adalah energi kinetik dan energi potensial.

Persamaan gerak dapat ditentukan dengan menggunakan persamaan Euler-Lagrange:

$$
\frac{d}{d t}\left(\frac{\partial L}{\partial \dot{\theta}}\right)=\frac{\partial L}{\partial \theta}
$$

dimana $\theta$ adalah sudut pendulum ke arah vertikal ke atas.

Berdasarkan gambar, diperoleh bahwa:

$$
\begin{aligned}
& x=l \sin \theta \\
& y=l \cos \theta
\end{aligned}
$$

sehingga

$$
\frac{d x}{d t}=\dot{x}=l(\cos \theta) \dot{\theta}
$$




$$
\frac{d y}{d t}=\dot{y}=-l(\sin \theta) \dot{\theta}
$$

Kecepatan sebagai besaran vektor dapat ditentukan dengan

$$
\begin{gathered}
v^{2}=\dot{x}^{2}+\dot{y}^{2} \\
v^{2}=l^{2} \dot{\theta}^{2} \cos ^{2} \theta+l^{2} \dot{\theta}^{2} \sin ^{2} \theta \\
v^{2}=l^{2} \dot{\theta}^{2}\left(\cos ^{2} \theta+\sin ^{2} \theta\right)
\end{gathered}
$$

Mengingat sifat trigonometri bahwa $\cos ^{2} \theta+\sin ^{2} \theta=1$, maka

$$
v^{2}=l^{2} \dot{\theta}^{2}
$$

Dari persamaan (1), Lagrangian dapat ditulis sebagai:

$$
L=\frac{1}{2} m l^{2} \dot{\theta}^{2}-m g l \cos \theta
$$

sehingga

$$
\begin{gathered}
\frac{\partial L}{\partial \theta}=m g l \sin \theta \\
\frac{\partial L}{\partial \dot{\theta}}=m l^{2} \dot{\theta}
\end{gathered}
$$

Sehingga Persamaan Euler-Lagrange menjadi:

$$
\begin{gathered}
\frac{d}{d t}\left(m l^{2} \dot{\theta}\right)=m g l \sin \theta \\
m l^{2} \ddot{\theta}=m g l \sin \theta
\end{gathered}
$$

Persamaan (16) adalah persamaan diferensial untuk sistem pendulum terbalik tanpa gaya tambahan. Jika terdapat gaya redam yang sebanding dengan kecepatan, persamaan gerak akan memuat suku redaman, $\gamma \frac{d \theta}{d t}$ dimana $\gamma$ adalah koefisien redaman. Jika terdapat juga gaya penggerak (driving force), persamaan juga akan memuat suku gaya penggerak menjadi:

$$
m l^{2} \ddot{\theta}+\gamma \dot{\theta}=m g l \sin \theta+C \cos \omega_{D} t(17)
$$

dimana $C$ adalah amplitudo dari gaya penggerak dan $\omega_{D}=\frac{d \phi}{d t}=\dot{\phi}$.

Bentuk tak berdimensi dari persamaan di atas adalah:

$$
\begin{gathered}
\ddot{\theta}+\frac{1}{q} \dot{\theta}=\sin \theta+a \cos \omega_{D} t \\
\ddot{\theta}=\sin \theta+a \cos \phi-\frac{1}{q} \dot{\theta}
\end{gathered}
$$

Persamaan (19) dapat dinyatakan dengan:

$$
\dot{\omega}=\sin \theta+a \cos \phi-\frac{1}{q} \omega
$$

\subsection{Transformasi Laplace untuk Menganalisis Sistem Pendulum Terbalik dengan Redaman dan Gaya Penggerak}

Kondisi awal dari sistem adalah:

$$
\omega(0)=0 ; \dot{\omega}(0)=0
$$

Misalkan $q=2, a=1$ dan $\quad \theta=\phi=\pi / 2$ maka persamaan diferensial (20) menjadi:

$$
\begin{gathered}
\dot{\omega}=1-\frac{1}{2} \omega \\
\mathcal{L}\{\dot{\omega}(t)\}=\mathcal{L}\left\{1-\frac{1}{2} \omega\right\} \\
s[\mathcal{L}\{\omega(t)\}-\omega(0)]=\mathcal{L}\{1\}-\frac{1}{2} \mathcal{L}\{\omega\} \\
s \omega(s)=\frac{1}{s}-\frac{1}{2} \omega(s) \\
\left(\frac{2 s+1}{2}\right) \omega(s)=\frac{1}{s} \\
\omega(s)=\frac{1}{s}\left(\frac{2}{2 s+1}\right) \\
\omega(s)=\frac{1}{s\left(s+\frac{1}{2}\right)} \\
\omega(s)=\frac{A}{s}+\left(\frac{B}{s+\frac{1}{2}}\right) \\
\omega(s)=\frac{(A+B) s+\frac{1}{2} A}{s\left(s+\frac{1}{2}\right)}
\end{gathered}
$$

Dengan cara substitusi dan eliminasi antara persamaan (28) dan (30) maka didapatkan $A=2$ dan $B=-2$ sehingga persamaan (29) menjadi:

$$
\omega(s)=\frac{2}{s}-\frac{2}{s+\frac{1}{2}}
$$

Persamaan (31) diselesaikan dengan invers Transformasi Laplace:

$$
\begin{gathered}
\mathcal{L}\{\omega(s)\}=2 \mathcal{L}\left\{\frac{1}{s}\right\}-2 \mathcal{L}\left\{\frac{1}{s+\frac{1}{2}}\right\} \\
\omega(t)=2\left(1-e^{-\frac{1}{2} t}\right)
\end{gathered}
$$


Dengan cara yang sama menggunakan transformasi diperoleh persamaan $\omega(t)$ seperti pada Tabel 1 .

Laplace untuk $\theta$ dan $\phi$ yang berbeda, maka

Tabel 1. Tabel Kecepatan Sudut untuk $\boldsymbol{\theta}$ dan $\boldsymbol{\phi}$ yang berbeda

\begin{tabular}{|c|c|c|c|c|c|c|c|c|}
\hline $\bar{\theta}$ & $\phi$ & $\omega(t)$ & $\theta$ & $\phi$ & $\omega(t)$ & $\theta$ & $\phi$ & $\omega(t)$ \\
\hline & 0 & $2\left(1-e^{-\frac{1}{2} t}\right)$ & \multirow{5}{*}{$\frac{\pi}{6}$} & 0 & $3\left(1-e^{-\frac{1}{2} t}\right)$ & \multirow{5}{*}{$\frac{\pi}{4}$} & 0 & $(\sqrt{2}+2)\left(1-e^{-\frac{1}{2} t}\right)$ \\
\hline \multirow{4}{*}{0} & $\frac{\pi}{6}$ & $\sqrt{3}\left(1-e^{-\frac{1}{2} t}\right)$ & & $\frac{\pi}{6}$ & $(\sqrt{3}+1)\left(1-e^{-\frac{1}{2} t}\right.$ & & $\frac{\pi}{6}$ & $(\sqrt{2}+\sqrt{3})\left(1-e^{-\frac{1}{2} t}\right)$ \\
\hline & $\frac{\pi}{4}$ & $\sqrt{2}\left(1-e^{-\frac{1}{2} t}\right)$ & & $\frac{\pi}{4}$ & $(\sqrt{2}+1)\left(1-e^{-\frac{1}{2} t}\right.$ & & $\frac{\pi}{4}$ & $2 \sqrt{2}\left(1-e^{-\frac{1}{2} t}\right)$ \\
\hline & $\frac{\pi}{3}$ & $1-e^{-\frac{1}{2} t}$ & & $\frac{\pi}{3}$ & $2\left(1-e^{-\frac{1}{2} t}\right)$ & & $\frac{\pi}{3}$ & $(\sqrt{2}+1)\left(1-e^{-\frac{1}{2} t}\right)$ \\
\hline & & $-2\left(1-e^{-\frac{1}{2} t}\right)$ & & $\frac{\pi}{2}$ & $-\left(1-e^{-\frac{1}{2} t}\right)$ & & $\frac{\pi}{2}$ & $\sqrt{2}\left(1-e^{-\frac{1}{2} t}\right)$ \\
\hline
\end{tabular}

\begin{tabular}{|c|c|c|c|c|c|}
\hline$\theta$ & $\phi$ & $\omega(t)$ & $\theta$ & $\phi$ & $\omega(t)$ \\
\hline \multirow{5}{*}{$\frac{\pi}{3}$} & 0 & $(\sqrt{3}+2)\left(1-e^{-\frac{1}{2} t}\right)$ & \multirow{5}{*}{$\frac{\pi}{2}$} & 0 & $4\left(1-e^{-\frac{1}{2} t}\right)$ \\
\hline & $\frac{\pi}{6}$ & $2 \sqrt{3}\left(1-e^{-\frac{1}{2} t}\right)$ & & $\frac{\pi}{6}$ & $(\sqrt{3}+2)\left(1-e^{-\frac{1}{2} t}\right)$ \\
\hline & $\frac{\pi}{4}$ & $(\sqrt{2}+\sqrt{3})\left(1-e^{-\frac{1}{2} t}\right)$ & & $\frac{\pi}{4}$ & $(\sqrt{2}+2)\left(1-e^{-\frac{1}{2} t}\right.$ \\
\hline & $\frac{\pi}{3}$ & $(\sqrt{3}+1)\left(1-e^{-\frac{1}{2} t}\right)$ & & $\frac{\pi}{3}$ & $3\left(1-e^{-\frac{1}{2} t}\right)$ \\
\hline & $\frac{\pi}{2}$ & $\sqrt{3}\left(1-e^{-\frac{1}{2} t}\right)$ & & $\frac{\pi}{2}$ & $2\left(1-e^{-\frac{1}{2} t}\right)$ \\
\hline
\end{tabular}

Grafik kecepatan sudut sebagai fungsi waktu untuk $\theta=\frac{\pi}{6}$ dan pada $0 \leq \phi \leq \pi$ dapat dilihat pada Gambar 3. Grafik kecepatan sudut sebagai fungsi waktu untuk $\phi=\frac{\pi}{6}$ dan pada $-\frac{\pi}{2} \leq \theta \leq \frac{\pi}{2}$ dapat dilihat pada Gambar 4. 


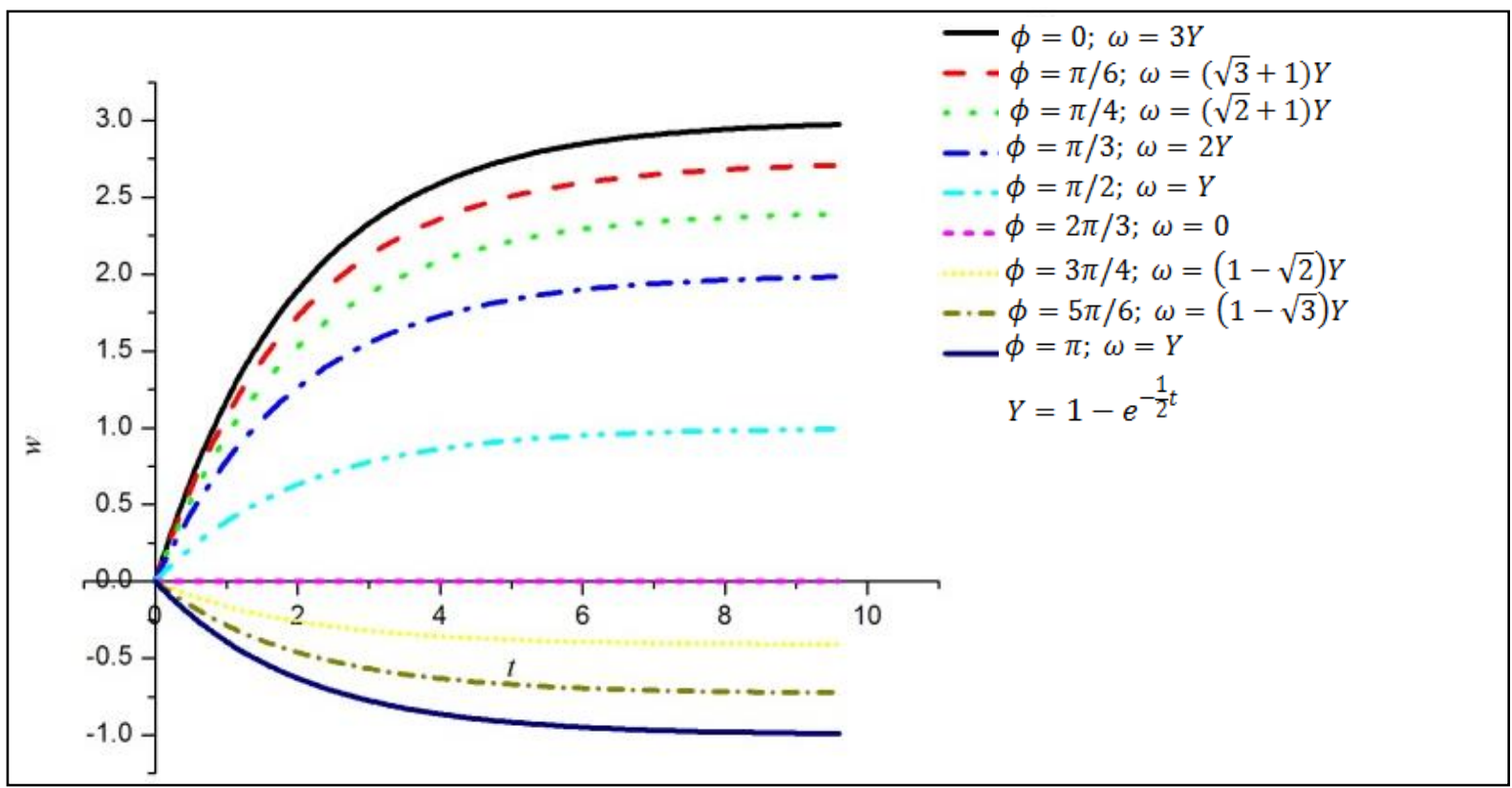

Gambar 3. Grafik Kecepatan Sudut Terhadap Waktu dengan Variasi $\boldsymbol{\phi}$ pada $\boldsymbol{\theta}=\boldsymbol{\pi} / \mathbf{6}$

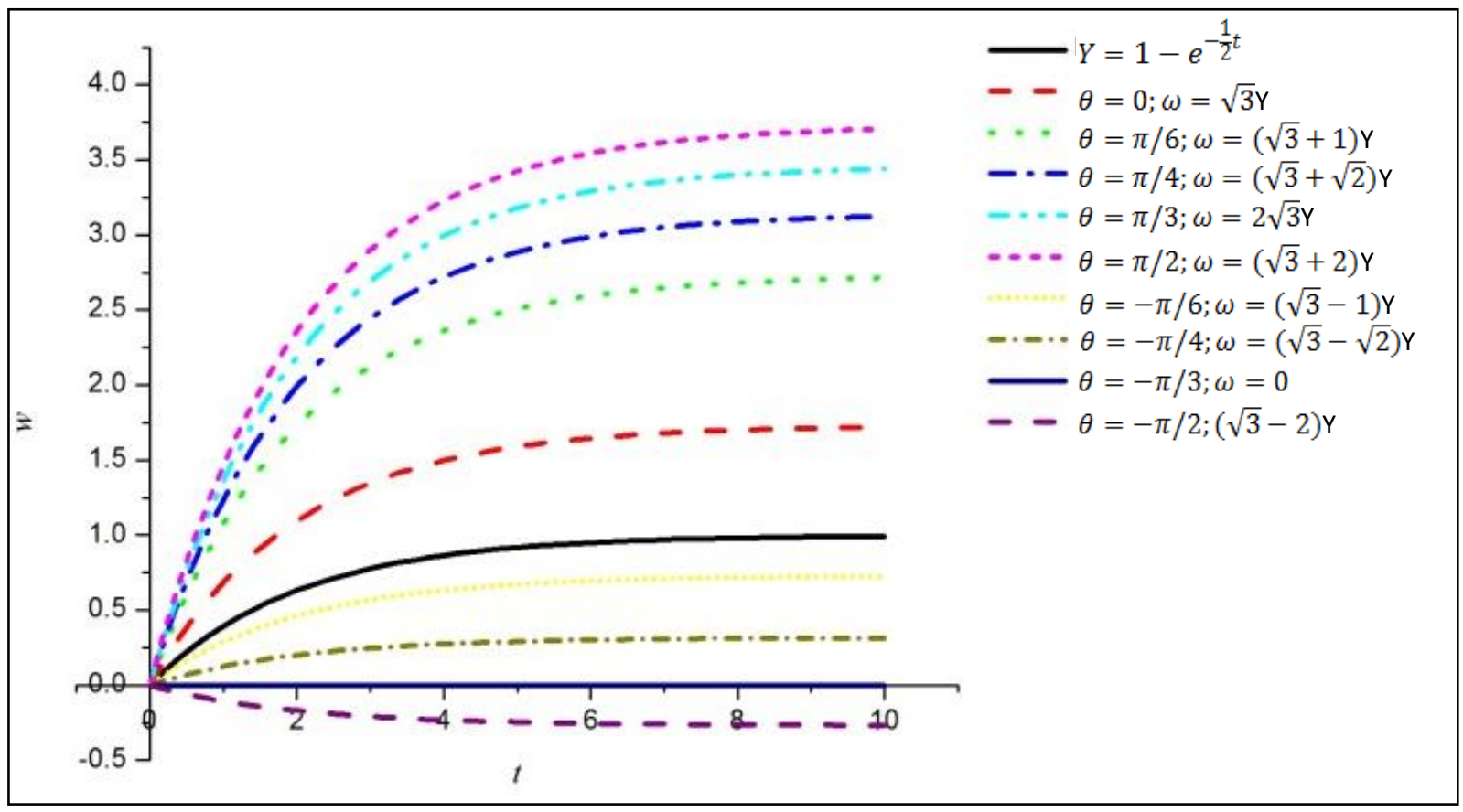

Gambar 4. Grafik Kecepatan Sudut Terhadap Waktu dengan Variasi $\boldsymbol{\theta}$

\section{Penutup}

Berdasarkan pembahasan, maka dapat disimpulkan bahwa transformasi Laplace dapat digunakan untuk menyelesaikan persamaan diferensial pada sistem pendulum terbalik dengan redaman dan gaya penggerak (driving force).

\section{Daftar Pustaka}

Agarana, M C, \& Agboola, O. O. (2015). Dynamic Analysis of Damped Driven Pendulum using Laplace Transform Method d T. International Journal of Mathematics and Computation, 26(3).

Agarana, Michael C., \& Ajayi, O. O. (2017).

Dynamic modeling and analysis of inverted pendulum using lagrangiandifferential transform method. In 
Proceeding of the World Congress on Engineering (Vol. 2230, hal. 1031-1036).

Appel, W. (2007). Mathematics for Physics and Physicists. New Jersey: New Jersey.

Arfken, G. B., \& Weber, H. J. (2016). Mathematical Methods for Physicists (7th editio). Florida: A Harcourt Science and Technology Company.

Arifin, A., Musthofa, M. W., \& Sugiyanto, S. (2013). Aplikasi Transformasi Laplace Pada Rangkaian Listrik. Jurnal Fourier, 2(1), 45. https://doi.org/10.14421/fourier.2013.21.4 5-61

Bandari, N., Hooshiar, A., Javaddargahi, M., \& Su, C. Y. (2017). Stabilization of Double Inverted Pendulum on a Cart: LQR Approach, 5(2), 149-153.

Boas, M. L. (2006). Mathematical Methods in the Physical Sciences (3rd editio). Hoboken: Kaye Pace.

Kusse, B. R., \& Westwig, E. A. (2006). Mathematical Physics, Applied Mathematics for Scientists and Engineers (2nd editio). Berlin: WILEY-VCH Verlag GmbH \& Co. KGaA.

Mandic, P. D., Lazarevic, M. P., Šekara, T. B., Cajic, M., \& Bucanovic, L. (2017). Stabilization of Double Inverted Pendulum System by Using a Fractional Differential Compensator. In 2017 29th Chinese Control And Decision Conference (CCDC), Chongqing (hal. 1911-1916). https://doi.org/10.1109/CCDC.2017.79788 29.

Michael, C., Agarana, C., Esther, T., \& Akinlabi, T. (2019). Lagrangian-Laplace Dynamic Mechanical Analysis and Modeling of Inverted Pendulum. In Procedia Manufacturing (Vol. 35, hal. 711-718). Elsevier B.V. https://doi.org/10.1016/j.promfg.2019.06.0 13
Minggani, F. (2019). Penerapan Transformasi Laplace Modifikasi Pada Persamaan Diferensial. In Prosiding Natinal Conference on Mathematics, Science, and Education (NACOMSE) (hal. 91-98).

Riley, K. F., Hobson, M. P., \& Bence, S. J. (2006). Mathematical Methods for Physics and Engineering (3rd editio). New York: Cambridge University Press.

Rizal, Y., \& Mantala, R. (2016). Keseimbangan Sistem Pendulum Terbalik Beroda. In Prosiding SNRT (Seminar Nasional Riset Terapan) (Vol. 5662, hal. 9-10).

Sablina, G. V., Stazhilov, I. V., \& Sazhin, A. I. (2015). Synthesis of double inverted pendulum on the cart system on the sliding modes method basis. In 2015 International Siberian Conference on Control and Communications, SIBCON 2015 Proceedings (hal. 2-6). https://doi.org/10.1109/SIBCON.2015.714 7201

Su, X., Xia, F., Liu, J., \& Wu, L. (2018). Eventtriggered fuzzy control of nonlinear systems with its application to inverted pendulum systems. Automatica, 94(1), 236-248. https://doi.org/10.1016/j.automatica.2018. 04.025

Tin, P. T., Minh, T. H. Q., Trang, T. T., \& Dung, N. Q. (2019). Using real interpolation method for adaptive identification of nonlinear inverted pendulum system. International Journal of Electrical and Computer Engineering, 9(2), 1078-1089. https://doi.org/10.11591/ijece.v9i2.pp.107 8-1089 